stable up to $50^{\circ}$. The temperature optimum for antithrombin activity is between 35 and $40^{\circ}$.

My thanks are due to Dr R. A. Kekwick for much helpful advice and encouragement; to him and Miss M. Mackay for supply of human blood products; and to Dr I. A. Galloway, Ministry of Agriculture Research Station, Pirbright, for supply of ox blood.

\section{REFERENCES}

Astrup, T. \& Darling, S. (1942). Acta physiol. scand. 4, 293.

Bodansky, O. (1937). J. biol. Chem. 120, 555.

Collingwood, B. J. \& MacMahon, M. T. (1912). J. Physiol. $45,119$.

Collingwood, B. J. \& MacMahon, M. T. (1913). J. Physiol. 47, 44.

Gerendas, M. (1948). Hung. acta physiol. 1, 7.

Herbert, F. K. (1940). Biochem. J. 34, 1554.

Howell, W. H. (1916). Harvey Lect. xii, 1.

Kekwick, R. A., Lyttleton, J. W., Brewer, E. \& Dreblow, E. S. (1951). Biochem. J. 49, 253.
Kekwick, R. A. \& Mackay, M. E. (1948). Proc. 1st Int. Congr. Biochem. p. 147.

Kekwick, R. A. \& Mackay, M. E. (1954). The separation of protein fractions from human plasma with ether. Spec. Rep. Ser. med. Res. Counc., Lond., no. 286. London: H.M. Stationery Office.

Kekwick, R. A., Mackay, M. E. \& Record, B. R. (1946). Nature, Lond., 157, 629.

Koller, F. \& Fritschy, W. (1947). Helv. med. acta, 14, 263. Landsberg, M. (1913). Biochem. Z. 50, 245.

Lenggenhager, K. (1935). Helv. med. acta, 1, 527.

Michaelis, L. (1930). J. biol. Chem. 87, 33.

Owren, P. (1947). 'The Coagulation of Blood', Oslo: Gundersen.

Philpot, J. St L. (1938). Nature, Lond., 141, 283.

Quick, A. J. (1938). Amer. J. Physiol. 123, 712.

Rettger, L. I. (1909). Amer. J. Physiol. 24, 406.

Stewart, J. D. \& Rourke, G. M. (1940). J. clin. Invest. 19, 695.

Tanturi, C. A. \& Wetzel, N. C. (1949). Amer. J. med. Sci. 217, 410.

Volkert, M. (1942). Acta physiol. scand. 5, suppl. xv.

Warner, E. D., Brinkhous, K. M. \& Smith, H. P. (1936). Amer. J. Physiol. 114, 667.

\title{
The Antithrombin Activity of Heparin
}

\author{
By J. W. LYTTLETON*
}

(Received 15 February 1954)

Since its discovery by MacLean (1916) heparin has been recognized as the most important naturally occurring anticoagulant. It seems well established that its action is twofold; it inhibits the transformation of prothrombin to thrombin when accompanied by a cofactor present in plasma (Brinkhous, Smith, Warner \& Seegers, 1939), and it inhibits the action of thrombin on fibrinogen. It is this second action of heparin as an antithrombin that is studied here.

\section{MATERIALS AND METHODS}

'Heparin Vitrum', Stockholm, with an activity of 100 units/ mg. dry weight (Murray \& Best, 1938) was dissolved in small amounts to give solutions of 100 units $/ \mathrm{ml}$. in veronal buffer, $\mathrm{pH} 7 \cdot 3, I=0 \cdot 15$ (Michaelis, 1930), and freshly diluted as required. Toluidine blue (British Drug Houses Ltd.) was dissolved in veronal buffer to give a solution of $50 \mathrm{mg} . / \mathrm{ml}$. Thrombin, fibrinogen, and defibrinated plasma were the same as those described in the previous paper (Lyttleton, 1954).

Measurement of antithrombin activity of heparin. To study the antithrombin effect of heparin, the type of experiment

* Beit Memorial Research Fellow, The Lister Institute, London. Present address: Department of Scientific and Industrial Research, Plant Chemistry Laboratory, Palmerston North, N.Z. was the same as described in the previous paper (Lyttleton, 1954). Thrombin was incubated at $37^{\circ}$ with heparin and any other material being studied, and the decay in thrombin activity was followed by allowing samples withdrawn after various time intervals to coagulate a standard fibrinogen solution at $37^{\circ}$.

\section{RESULTS}

\section{Action of heparin on thrombin}

Samples (5.0 ml.) of thrombin (6.7 units $/ \mathrm{ml}$.) were incubated with various concentrations of heparin at $37^{\circ}$. Some of the curves thus obtained are shown in Fig. 1.

It is plain that heparin exerts two different effects on this thrombin preparation: (i) a slow progressive inactivation, predominant at low concentrations of heparin, and (ii) an immediate drop in thrombin activity, predominant at concentrations of heparin above 1.0 unit $/ \mathrm{ml}$.

From 0.05 to 0.5 unit $/ \mathrm{ml}$. of heparin, the rate of progressive inactivation of thrombin remains almost independent of heparin concentration, though this finding is not illustrated in Fig. 1. At 0.5 unit $/ \mathrm{ml}$. of heparin an immediate decrease in thrombin activity was observed, and further increase in heparin concentration caused a greater immediate decrease in 
thrombin activity, whilst the subsequent rate of progressive inactivation was reduced. Thus after periods of $100 \mathrm{~min}$. those solutions containing stronger heparin (Fig. 1, curves 5 and 6) had more thrombin activity than those with weaker heparin (curves 2 and 3 ), a reversal of the position shown immediately after mixing. These two different actions were subjected to further study.

Immediate reduction in thrombin activity caused by larger amounts of heparin. This section deals with the effect on thrombin of heparin in concentrations greater than 2 units $/ \mathrm{ml}$. The magnitude of the apparent immediate thrombin inactivation does not increase linearly with increasing concentration of heparin, but approaches a limiting value as indicated in Fig. 1.

Provided that the coagulating mixture contained the same concentration of heparin, the same prolonged value of the coagulation time was found whether the heparin was originally added to the fibrinogen or to the thrombin. The effect was therefore a rapid one, occurring in the few seconds before coagulation took place.

Progressive dilutions of two thrombin samples, one containing no heparin and the other 10 units/ ml., gave coagulation times which coincided when the dilution had reduced the heparin concentration to $\mathbf{0 . 2}$ unit $/ \mathrm{ml}$, indicating that the effect was reversible on dilution. This reversibility was also indicated by experiments with toluidine blue which removes heparin by combining with it (Jorpes, 1936). Unfortunately toluidine blue produces an immediate apparent increase in thrombin activity followed by a progressive decay, so conditions must be carefully controlled to produce a significant result.

Increase of the ionic strength of the solution containing thrombin from 0.15 to 0.5 led to a reduced drop in apparent thrombin strength when heparin was added. A new calibration of coagulation time against thrombin units was necessary to determine the effect due to the change in ionic strength alone. It was shown that at $I=0 \cdot 15$, 8 heparin units $/ \mathrm{ml}$. reduced the activity of a thrombin solution of 12 units $/ \mathrm{ml}$. by $45 \%$, while at $I=0.5$ the reduction was only $10 \%$.

These results are all consistent with the hypothesis that thrombin will combine with heparin as a result of electrostatic attraction between the molecules to form a reversible thrombin-heparin complex which has less activity than the uncombined thrombin. This complex dissociates on dilution, increasing the ionic strength, or removing heparin from the system.

Evidence for the existence of the complex was obtained by carrying out an electrophoretic separation on two samples of thrombin, one containing no heparin, and the other containing
13 units $/ \mathrm{ml}$. The electrophoretic patterns produced were identical in the two cases and exhibited three components. Since their mobilities were too close to permit satisfactory separation, a sharply defined pigmented layer coinciding with the middle peak was chosen as the point at which to cut the pattern. The thrombin activity of the leading (anode) and trailing (cathode) sections of the separated fractions was examined under the usual conditions. The results are given in Table 1. No attempt was made to remove heparin from the fractions obtained by the second separation. It was presumably present at least in the leading fraction and would exhibit its usual delaying effect on coagulation carried out with this fraction. Despite this, the addition of heparin caused the transfer of a large part of the thrombin activity from the trailing to the leading fraction. As all other factors were kept constant during these

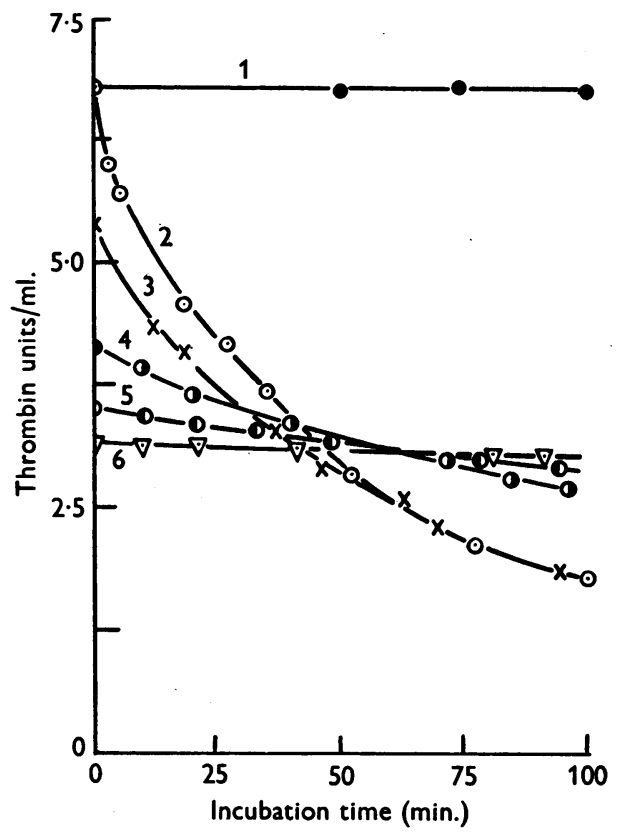

Fig. 1. Action of heparin on thrombin. Constant initial thrombin concentration (6.7 units/ml.). Heparin concns. (units/ml.): curve (1) 0.0 ; (2) 0.073 ; (3) 0.66 ; (4) 4.0 ; (5) $10 \cdot 0$; (6) 40.0. Volumes adjusted with veronal buffer.

\section{Table 1. Thrombin activity of electrophoretically separated fractions}

See text for experimental details.

$\begin{array}{lcc}\text { Material } & \text { Coagulation times (sec.) } \\ \begin{array}{c}\text { Leading } \\ \text { fraction } \\ \text { (anode) }\end{array} & \begin{array}{c}\text { Trailing } \\ \text { fraction } \\ \text { (cathode) }\end{array} \\ \text { Thrombin alone } & 210 & 9 \\ \text { Thrombin + heparin } & 13 & 19\end{array}$


two runs, the increased mobility of the thrombin must be due to the action of heparin, which is consistent with the suggestion that a complex is formed between the two substances which, because of the high negative charge on the heparin, migrates more rapidly than thrombin alone.

Progressive decay of thrombin due to smaller amounts of heparin. This section deals with the action on thrombin of heparin in concentrations below $0.5 \mathrm{unit} / \mathrm{ml}$. The rate of the progressive decay reaction is not appreciably influenced by the concentration of heparin until this is sufficiently great to produce considerable heparin-thrombin complex formation. Fig. 1 indicates that beyond this point the rate of progressive decay of thrombin decreases, as if the complex formation exerted a stabilizing influence on the thrombin. The loss in thrombin activity produced by heparin as a result of this decay is not reversible on removal of the heparin; this was demonstrated by addition of toluidine blue at various intervals during the progress of the reaction, which did not restore the thrombin activity to the initial level.

The fact that fibrin clots produced by thrombin mixtures containing heparin would lyse considerably more rapidly at $37^{\circ}(1-2 \mathrm{hr}$.) than those which were free from heparin (12-24 hr.) suggested that the cause of the thrombin decay might be due either to activation of plasminogen in the thrombin preparation by heparin, or to an increase in suscepti-

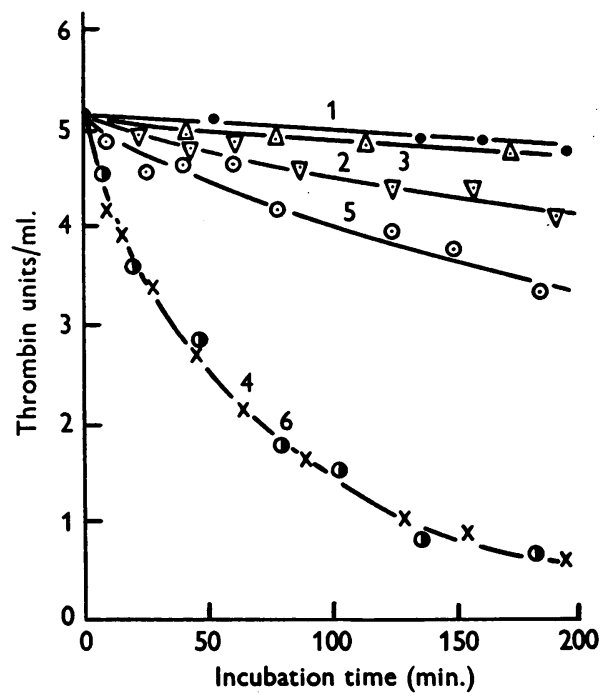

Fig. 2. Effect of serum euglobulins on action of heparin on thrombin. Initial thrombin concn. 5.1 units/ml. Volume of all mixtures made up to $5 \mathrm{ml}$. with veronal buffer. Curve (1) control; (2) $0.5 \mathrm{ml}$. euglobulin soln.; (3) $0.5 \mathrm{ml}$.

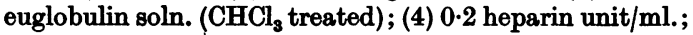
(5) 0.2 heparin unit/ml. $+0.5 \mathrm{ml}$. euglobulin soln.; (6) 0.2 heparin unit/ml. $+0.5 \mathrm{ml}$. euglobulin soln. $\left(\mathrm{CHCl}_{3}\right.$ treated). bility of thrombin to plasmin present. This was tested by adding to the thrombin-heparin system fractions of human serum containing plasminogen and plasmin respectively. These were prepared by diluting serum to 20 vol. with distilled water and lowering the $\mathrm{pH}$ to 5.3 with $0.5 \mathrm{~N}$ acetic acid. The resulting precipitate, redissolved to $1 / 10$ original volume in veronal buffer and neutralized, possessed only very slight antithrombin activity, and is referred to as serum euglobulin. On incubation with chloroform at $37^{\circ}$ for $3 \mathrm{hr}$. the plasminogen contained in this fraction became activated to plasmin.

The effect of adding euglobulin before and after treatment with chloroform, that is plasminogen or plasmin, to the heparin-thrombin system is shown in Fig. 2. Whereas the plasmin fraction had no effect on the action of heparin on thrombin, the plasminogen fraction produced, unexpectedly, considerable inhibition of the thrombin decay. It seems therefore that heparin does not act on thrombin through the plasma proteolytic enzyme plasmin. The component of the euglobulin fraction which is responsible for the inhibition of the thrombin inactivation has not been completely identified, but electrophoretic fractionation of the euglobulin showed that the inhibitory activity lay in the more mobile of the two components observed at $\mathrm{pH} 8$.

\section{Action of defibrinated plasma (DFP) on thrombin in the presence of heparin}

Immediate effect (varying heparin concentration; constant DFP and initial thrombin). The curves of Fig. $3(a)$ and $(b)$ show the effect of varying the heparin concentration in the system thrombinDFP-heparin. In group $(a)$ even at very low concentrations of heparin there is a rapid fall in thrombin activity to a definite level, the time of fall increasing from less than 30 sec. at heparin concentration above $0.1 \mathrm{unit} / \mathrm{ml}$. to approx. $3 \mathrm{~min}$. at a concentration of $0.025 \mathrm{unit} / \mathrm{ml} .\left(0.25 \times 10^{-6} \mathrm{~g} . / \mathrm{ml}\right.$. $)$

Group (b) indicates that as the concentration of heparin increases beyond this range the initial drop in thrombin activity increases, because the effect of heparin-thrombin complex formation is added to that of DFP in the presence of heparin.

To study the immediate action of DFP on thrombin in the presence of heparin, it is therefore advisable to use a heparin concentration of about $0 \cdot 1 \mathrm{unit} / \mathrm{ml}$. In this region the initial drop in thrombin activity is rapid, and there is no appreciable heparin-thrombin complex formation.

Immediate effect (varying DFP concentration; constant heparin and initial thrombin). Mixtures containing 10 units $/ \mathrm{ml}$. thrombin, $0.1 \mathrm{unit} / \mathrm{ml}$. heparin and varying amounts of DFP were assayed for thrombin activity every $2 \mathrm{~min}$. during $10 \mathrm{~min}$., and the data obtained extrapolated to zero time to

Bioch. 1954, 58 
give a measure of the thrombin inactivated by the immediate action of DFP in the presence of heparin. In Fig. 4, curve 1, the thrombin inactivated at zero time is plotted against concentration of DFP, the curve obtained approaching linearity. Provided that the concentration of heparin is $0.2 \mathrm{unit} / \mathrm{ml}$. or less, an almost linear relationship exists between the concentration of DFP in a mixture and the amount of thrombin inactivated in the first 30 sec.

If heparin at higher concentrations is used in this experiment, two control solutions are neccssary, one containing thrombin alone $(A)$, and the other containing thrombin plus heparin $(B)$. On adding DFP to the thrombin and heparin, a drop in throm-

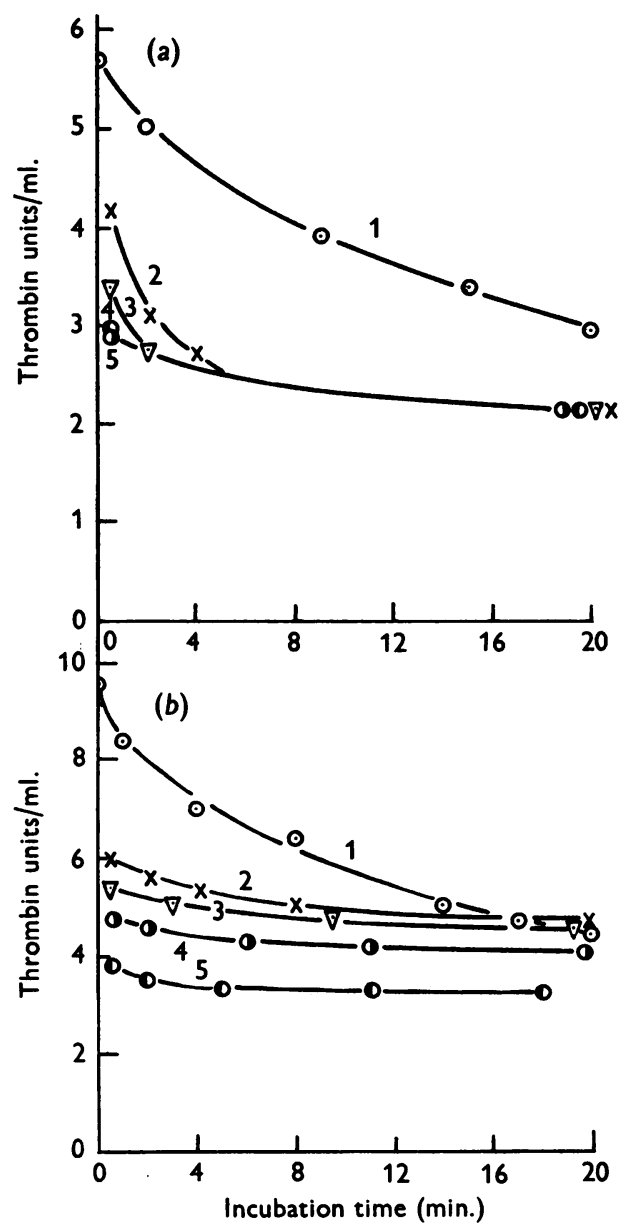

Fig. 3. Immediate action of DFP on thrombin in presence of heparin. (a) Initial thrombin concn. 5.7 units $/ \mathrm{ml}$.; DFP concn. $0.05 \mathrm{ml} . / \mathrm{ml}$. soln.; solution volume $5 \mathrm{ml}$; heparin concns. (units/ml.) : curve (1) 0 ; (2) 0.025; (3) 0.05 ; (4) 0.1 ; (5) $0 \cdot 2$. (b) Initial thrombin concn. 9.5 units $/ \mathrm{ml}$; DFP concn. $0.08 \mathrm{ml} . / \mathrm{ml}$. soln.; solution volume $5 \mathrm{ml}$; heparin concns. (units $/ \mathrm{ml}$.) : curve (1) 0 ; (2) 0.11 ; (3) 0.33 ; (4) $1 \cdot 0$; (5) $3 \cdot 0$. bin activity occurred; and if the apparent thrombin inactivation relative to the control solution $(B)$ was plotted against the amount of DFP added, a curve such as curve 2, Fig. 4, was obtained, the slope becoming further removed from that of curve 1 as the heparin concentration was increased.

This departure from curve 1 may be explained by assuming that relative to the control $(A)$ the amount of thrombin inactivated by DFP, even in the presence of strong heparin, is the same as in curve 1 , and that the remaining thrombin undergoes com. plex formation with heparin to give a further reduction in thrombin activity in the same ratio as that between controls $(A)$ and $(B)$, the decrease in activity for curve 2 being $40 \%$. The thrombin activities predicted on this assumption agree with those measured.

Immediate effect (varying thrombin concentration; constant heparin and DFP). The immediate thrombin inactivation produced in these circumstances is illustrated in Table 2, which shows the

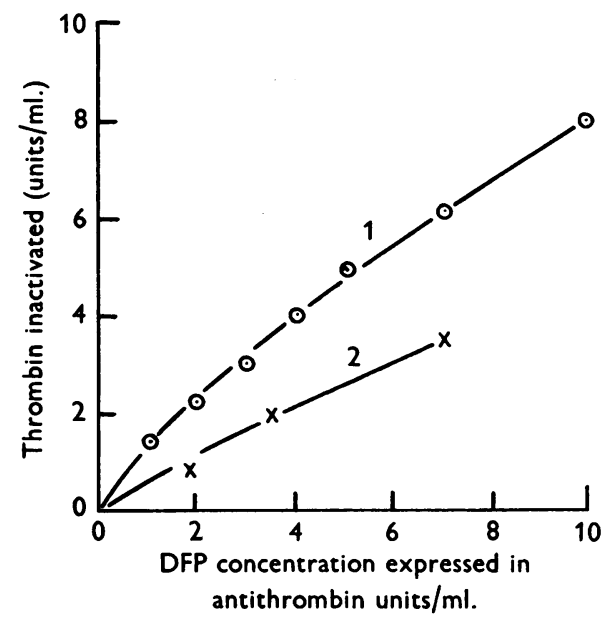

Fig. 4. Immediate action of DFP on thrombin in presence of heparin. Curve 1: heparin concn. $0.1 \mathrm{unit} / \mathrm{ml}$.; initial thrombin concn. 10 units $/ \mathrm{ml}$. Curve 2: heparin concn. 3.0 units/ml.; initial thrombin concn. $10 \mathrm{units} / \mathrm{ml}$. Volumes adjusted with veronal buffer.

\section{Table 2. Thrombin inactivation by $D F P$ and heparin}

$5 \mathrm{ml}$. samples of solutions containing $0 \cdot 1$ heparin unit/ ml., 5.0 antithrombin units/ml. (DFP), and varying thrombin units $/ \mathrm{ml}$., incubated at $37^{\circ}$.

$\begin{array}{cc}\begin{array}{c}\text { Initial thrombin } \\ \text { concn. } \\ \text { (units/ml.) }\end{array} & \begin{array}{c}\text { Thrombin } \\ \text { inactivated, } \\ \text { in } 30 \text { sec. } \\ \text { (units/ml.) }\end{array} \\ 15 \cdot 6 & 5 \cdot 0 \\ 10 \cdot 7 & 5 \cdot 1 \\ 8 \cdot 0 & 5 \cdot 0 \\ 5 \cdot 7 & 4 \cdot 8 \\ 2 \cdot 8 & 2 \cdot 8\end{array}$


effect of adding heparin and DFP in constant amounts to a series of thrombin solutions. The amount of thrombin inactivated by the initial rapid reaction is apparently independent of the initial thrombin concentration.

Subsequent progressive decay of thrombin activity. After the immediate inactivation considered above has taken place, further change in thrombin activity is influenced by at least two factors: the action of the antithrombin remaining in the DFP, and the progressive action of the heparin itself. Fig. 5 shows examples of thrombin decay curves obtained when the amount of heparin present in the system was varied. The thrombin preparation used in these experiments was less susceptible to the progressive action of heparin alone than the thrombin used in the experiments of Fig. 1, as shown by the reduced rate of decay in the corresponding curves. The reason for this reduced susceptibility is not known, but the thrombin preparation may have contained a larger amount of the heparin-inhibiting globulin. The use of this particular material reduced the decay due to heparin alone, and allowed the decay due to the remaining antithrombin to become more prominent.

The immediate change in the thrombin activity as the heparin concentration is varied is of the same type as that already illustrated in Figs. 1 and 3. The rate of the subsequent inactivation in the presence of DFP then decreases as the heparin concentration increases, so that after a sufficient time (150 $\mathrm{min}$.) has elapsed, the thrombin concentrations in curves 6-8 (Fig. 5) are in reverse order to those measured earlier ( $5 \mathrm{~min}$.). It is probable that as the heparin

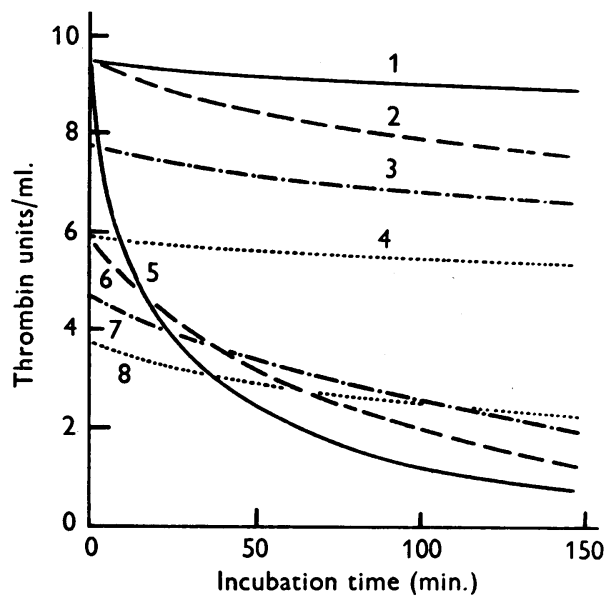

Fig. 5. Inactivation of thrombin by DFP in presence of heparin. Constant initial thrombin concn. 9.5 units $/ \mathrm{ml}$. Curves 1-4, no DFP; curves 5-8 DFP added to give 3.5 antithrombin units $/ \mathrm{ml}$. Heparin concns. (units/ml.): curves (1) and (5) 0 ; (2) and (6) 0.1 ; (3) and (7) 1.0 ; (4) and (8) 3.0. Volumes adjusted with veronal buffer. concentration increases, heparin-thrombin complex formation occurs to an increasing extent, and this complex may well be less sensitive than free thrombin to the action of any antithrombin remaining in the system. As the free thrombin in equilibrium with the complex is inactivated, the complex will presumably dissociate to liberate more thrombin, giving an apparently reduced decay rate of thrombin activity.

It is also possible that the antithrombin activity of the mixture may be reduced by the reaction resulting in the immediate inactivation of thrombin. The role of antithrombin in this process will be discussed more fully later, but it will be noticed that after the first $10 \mathrm{~min}$. the mixture containing DFP but no heparin (Fig. 5, curve 5) inactivates thrombin at a greater rate than the mixture containing DFP and 0.1 heparin unit/ml. (curve 6), despite the fact that heparin itself contributes to the progressive thrombin decay. This indicates that at least a part of the antithrombin activity of the DFP has been removed by the initial rapid reaction in the presence of heparin.

Addition of toluidine blue to the system to remove the heparin would not simplify matters by allowing the decay due to remaining antithrombin action alone to be studied, as the toluidine blue itself produces a decay in thrombin activity.

\section{Heparin cofactor}

The results suggest that the immediate inactivation of thrombin is due to a combination, in the presence of heparin, between thrombin and some factor present in DFP; this factor will be referred to as 'heparin cofactor'.

An experiment carried out by mixing thrombin, heparin, DFP, and toluidine blue in different sequences showed that unless thrombin, heparin, and DFP were present simultaneously no inactivating combination took place. If heparin, after a short incubation with either thrombin or DFP, was removed by the addition of toluidine blue, the subsequent addition of DFP or thrombin resulted in no immediate drop in thrombin activity. Either the heparin is bound irreversibly in the thrombincofactor complex, or it acts merely as a catalyst in the formation of this complex. This experiment did not decide between these possibilities.

Estimation of heparin cofactor. On the basis of Fig. 4, which shows that a definite amount of DFP in the presence of a low concentration of heparin $(0.1 \mathrm{unit} / \mathrm{ml}$.) will produce immediate inactivation of a definite amount of thrombin, a quantitative estimation of heparin cofactor may be made by measuring thrombin inactivation under these conditions. By analogy with the antithrombin unit, $1 \mathrm{ml}$. DFP is defined as containing 50 units of cofactor. 


\section{Interrelation of antithrombin and heparin cofactor}

Heparin cofactor and antithrombin have been considered to be distinct so far in this paper, but it is possible that they may be identical, a view proposed by Quick (1938) and Seegers (1942), and that heparin catalyses the action between thrombin and antithrombin. Evidence will now be considered leading to a choice between these alternatives.

Qualitative aspects. In general the cofactor follows antithrombin when DFP is fractionated by precipitation or electrophoretic separation. Experiments similar to those described for antithrombin (Lyttleton, 1954) established that heparin cofactor is an $\alpha$-globulin, and that albumin, $\beta$ - and $\gamma$ globulin are inactive. Electrophoretically separated albumin $+\alpha$-globulin fractions from DFP showed the same antithrombin : cofactor ratio as unfractionated DFP. However, the $\alpha$-globulin-rich precipitate prepared by fractionation with ether (Lyttleton, 1954) had a cofactor activity 2.5 times that of DFP, some $30 \%$ greater than the relative antithrombin activity $(1 \cdot 92)$.

Any reaction which consumes one factor alters the other. If the antithrombin content of DFP is reduced by incubating with thrombin, the amount of cofactor remaining in the DFP is simultaneously decreased. Also as already mentioned (Fig. 5) the immediate reaction of cofactor in DFP in the presence of heparin seems to reduce the amount of antithrombin remaining. These two effects are shown more directly by the following experiments. In the first, heparin was added to a series of thrombin-DFP mixtures after different periods of incubation at $37^{\circ}$. During the interval, before the addition of heparin, the usual progressive thrombin decay took place; when heparin was added a rapid fall in thrombin activity occurred, its extent depending on the amount of cofactor remaining in the solution. It is evident from curves 4-7 in Fig. 6 that as the thrombin-antithrombin reaction proceeded, and antithrombin was used up, the amount of heparin cofactor available also decreased.

In the second experiment the rate of decay of three thrombin solutions of 5.5 units $/ \mathrm{ml}$. was studied (Fig. 7). One of these solutions contained DFP, another contained heparin, and the third was formed from a stronger thrombin solution to which both heparin and DFP had been added, the resulting rapid fall in thrombin activity due to combination with heparin cofactor leaving approximately 5.5 units/ml., together with the remaining components of DFP. The rate of decay of these solutions indicated that removal of cofactor from DFP reduced its ability to act as a progressive antithrombin, curve 2 decaying less rapidly than curve 4.

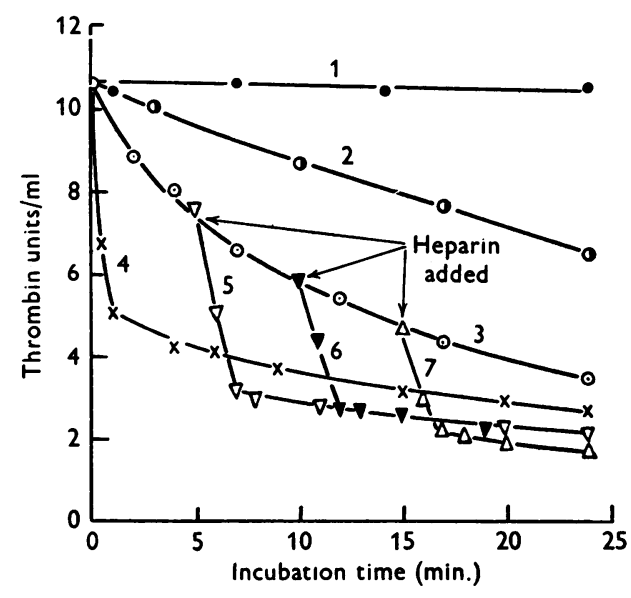

Fig. 6. Reduction of available heparin cofactor during inactivation of thrombin by DFP. All solutions contained $1 \mathrm{ml}$. thrombin (53 units $/ \mathrm{ml}$.) and were made up to $5 \mathrm{ml}$. with veronal buffer. Curve (1) control; (2) $0.05 \mathrm{ml}$. heparin (5 units $/ \mathrm{ml}$ ); (3) $0.5 \mathrm{ml}$. DFP; (4) $0.5 \mathrm{ml}$. DFP + 0.05 ml. heparin (added after 0 min.); (5) $0.5 \mathrm{ml}$. DFP + 0.05 ml. heparin (added after 5 min.); (6) $0.5 \mathrm{ml}$. DFP + 0.05 ml. heparin (added after $10 \mathrm{~min}$.); (7) $0.5 \mathrm{ml}$. $\mathrm{DFP}+0.05 \mathrm{ml}$. heparin (added after $15 \mathrm{~min}$.).

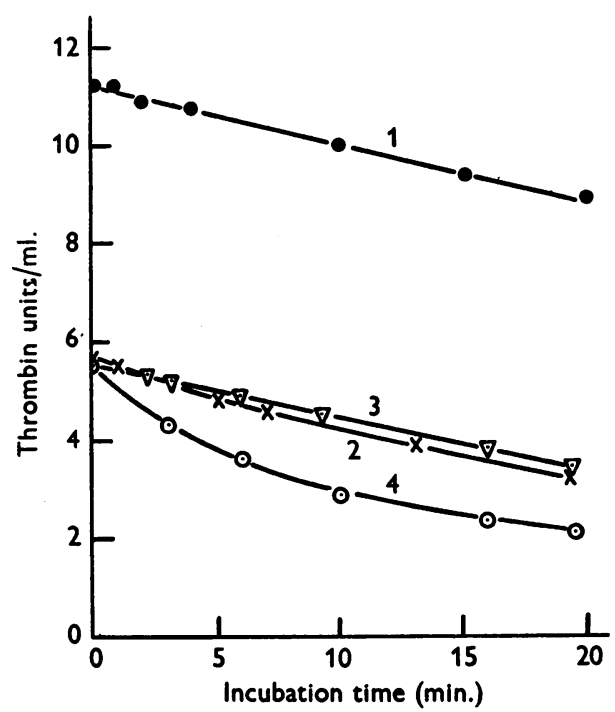

Fig. 7. Reduction of antithrombic action of DFP by removal of heparin cofactor. The curves correspond to the following mixtures (volumes in $\mathrm{ml}$.):

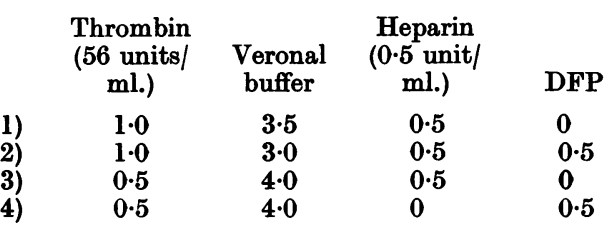


Further evidence suggesting that the normal antithrombin activity of DFP and the action in the presence of heparin may be related lies in the fact that toluidine blue (an anti-heparin) reduces the rate of thrombin inactivation by normal antithrombin when added to the system DFP-thrombin. A quantitative measure of the effect would require a more complete study of the inactivation of thrombin caused by toluidine blue alone, but if this is disregarded, $0 \cdot 1 \mathrm{mg}$. toluidine blue $/ \mathrm{ml}$. is found to reduce the apparent antithrombin activity of DFP by $35 \%$.

Quantitative aspects. It is difficult, because of the direct action of heparin on thrombin, to estimate the amount of antithrombin remaining in a DFPthrombin-heparin mixture when the cofactor has been used up; but the converse estimation of the cofactor remaining after removal of antithrombin

Table 3. Inactivation of antithrombin and heparin cofactor on incubation with thrombin

$\begin{array}{ccc}\begin{array}{c}\text { Thrombin units } \\ \text { inactivated }\end{array} & \begin{array}{c}\text { Antithrombin } \\ \text { units remaining }\end{array} & \begin{array}{c}\text { Heparin } \\ \text { cofactor units } \\ \text { remaining }\end{array} \\ 0 & 26 & 23 \\ 25 & 15 & 7 \\ 50 & 9 \cdot 5 & 3 \\ 75 & 5 & 0\end{array}$

Table 4. Progressive decrease in antithrombin and heparin cofactor during inactivation of thrombin

$\begin{array}{ccc}\text { Time } & \begin{array}{c}\text { Antithrombin } \\ \text { (min.) }\end{array} & \begin{array}{c}\text { units present } \\ \text { cofactor units } \\ \text { present }\end{array} \\ 0 & 5 \cdot 0 & 5 \cdot 2 \\ 5 & 3 \cdot 8 & 4 \cdot 2 \\ 10 & 3 \cdot 3 & 3 \cdot 2 \\ 15 & 3 \cdot 1 & 1 \cdot 7\end{array}$

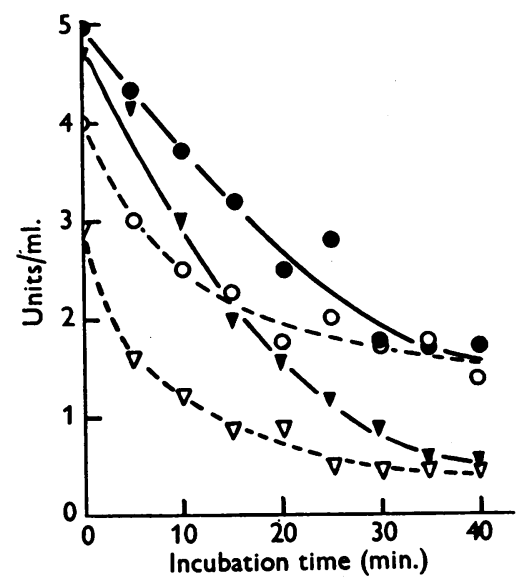

Fig. 8. Decay of antithrombin and heparin cofactor. Initial activity in all cases 5 units/ml. and $O$, antithrombin; $\nabla$ and $\nabla$, heparin cofactor. $\bigcirc, \nabla$, decay at $\mathrm{pH} 7,57^{\circ} ; \mathrm{O}, \nabla$, decay at $\mathrm{pH} 4 \cdot 5,37^{\circ}$. may readily be carried out. $0.5 \mathrm{ml}$. DFP was incubated with $0,25,50$, and 75 units of thrombin for $18 \mathrm{hr}$. at room temperature, after which time less than $0 \cdot 1$ unit thrombin remained. The amounts of antithrombin and heparin cofactor remaining in each solution were determined (Table 3).

A similar type of analysis is illustrated in Fig. 6. By measuring the percentage thrombin inactivation during successive $10 \mathrm{~min}$. intervals in curve 3 , the variation in antithrombin content with time may be calculated, while from the discontinuities in curves 4-7 the amount of heparin cofactor remaining after a given time may be calculated. The results obtained in this way are given in Table 4.

These results show that antithrombin and heparin cofactor cannot be identical: a view supported by a study of the rate of decay of the two factors.

Decay of antithrombin and heparin cofactor. This was studied under two sets of conditions. In the first case, DFP was heated to $57^{\circ}$, and $2 \mathrm{ml}$. samples were withdrawn and mixed with equal volumes of cold veronal buffer after successive $5 \mathrm{~min}$. intervals. The antithrombin and cofactor contents were later measured. In the second case, DFP at $37^{\circ}$ was acidified to $\mathrm{pH} 4.75$ with $0.2 \mathrm{~N}-\mathrm{HCl}$. Samples were withdrawn in the same way, and added to buffer to which enough $\mathrm{NaOH}$ had been added to produce a pH of $7 \cdot 3$ on mixing. The two activities were later measured. Both results are shown in Fig. 8. It is clear that the cofactor is more labile than the antithrombin in both the experiments, and from all these considerations it must be concluded that, though antithrombin and heparin cofactor are closely related, they cannot be identical.

\section{DISCUSSION}

It has been shown that heparin has a direct effect on thrombin, independent of its more important antithrombic action in the presence of a plasma cofactor. At heparin concentrations above 2.0 units/ ml. there is good evidence that heparin-thrombin complex formation occurs, the thrombin activity being thereby reduced. The mechanism of the progressive inactivation produced by lower concentrations of heparin has not yet been established.

In the presence of heparin concentrations of more than $0.05 \mathrm{unit} / \mathrm{ml}$. the action of defibrinated plasma on thrombin changes from a progressive to an immediate inactivation, the extent of which depends only on the concentration of defibrinated plasma. The simplest hypothesis to explain this is that of Seegers (1942) who suggested that antithrombin could combine only with a definite amount of thrombin, and that the action of heparin was merely catalytic. This implies that antithrombin and heparin cofactor are identical. This hypothesis, however, does not fully explain the observed facts. 
Defibrinated plasma alone can ultimately inactivate considerably more thrombin than is immediately inactivated in the presence of heparin (Fig. 5) so that, even if heparin does catalyse a combination between thrombin and antithrombin, it does not utilize to the full the capacity of defibrinated plasma to inactivate thrombin. After reacting with thrombin in the presence of heparin, defibrinated plasma is capable of inactivating still more thrombin though its potency is considerably reduced. Increasing the heparin concentration does not result in an increase in the immediate thrombin inactivation, apart from the effect due to heparin alone, so the remaining progressive antithrombin action cannot be converted into an immediate one by the action of heparin.

It seems necessary to postulate two processes which take place during inactivation of thrombin by defibrinated plasma: (i) an inhibitory combination, catalysed by heparin; (ii) a progressive inactivation, not catalysed by heparin. The first of these reactions is due to heparin cofactor, and leads to immediate thrombin inactivation in the presence of heparin of concentrations above 0.05 unit $/ \mathrm{ml}$. It has been shown, however, that if the heparin concentration is decreased below this, the rate of the initial inactivation of thrombin is decreased (Fig. $3 a$ ).

It has been claimed (Jaques, Monkhouse \& Stewart, 1949) that human blood normally contains heparin in concentrations of the order of $0.0001 \mathrm{mg} . /$ $\mathrm{ml}$. or 0.01 unit $/ \mathrm{ml}$. It is probable that in the presence of this very small amount of heparin the first reaction will take place even more slowly, at a rate comparable with the action of progressive antithrombin. Addition of heparin to the system accelerates a process that normally takes some minutes, thereby producing rapid inactivation. As it is not known whether this substance would react in the complete absence of heparin, it will still be referred to as heparin cofactor.

The second reaction postulated, a progressive inactivation not catalysed by heparin, may be due either to a second inhibitory combination or to an enzymic inactivation of thrombin which is ultimately slowed down in some way, possibly due to inhibition by end products of the reaction. This is evident from the results obtained on incubating defibrinated plasma with an excess of thrombin for a long period, when progressive thrombin inactivation ultimately ceases. For convenience the substance involved in this reaction will be called thrombin inactivator.

If this hypothesis is accepted, it is clear that when a measurement is made on the 'antithrombin' of defibrinated plasma both reactions are involved. When, however, the heparin cofactor is measured by immediate thrombin inactivation, it is only the first reaction involving inhibitory combination that is concerned. In the light of this, many of the observed facts in this and the previous paper (Lyttleton, 1954) may be explained.

The decrease in value of the first-order reaction constants with time in the reaction between antithrombin and thrombin may be ascribed to the fact that both the heparin cofactor and the thrombin in. activator are initially involved; but after a time the cofactor is saturated by combination with thrombin and the inactivator continues its action alone. The differences in stability of heparin cofactor and antithrombin are due to the fact that the antithrombin consists of both the cofactor and thrombin inactivator of which the former is the more rapidly destroyed. The reduction in antithrombin produced by incubation of defibrinated plasma with thrombin again involves both factors, and the more readily saturated heparin cofactor will be removed first from the system as the amount of thrombin incubated is increased, leaving mainly thrombin inactivator. Evidence of this is shown in the analysis of Fig. 6 already quoted (Table 4). The antithrombin and heparin cofactor both fall rapidly at first, but the antithrombin later falls more slowly. This is consistent with an antithrombin consisting of both cofactor (more rapidly removed) and thrombin inactivator, the action of which becomes more prominent as the cofactor disappears.

Several criticisms may be levelled at this hypothesis. In the first place, it has been shown that, even after extensive fractionation of defibrinated plasma involving ether precipitation followed by electrophoretic separation, the thrombin inactivation produced seems to follow the same kinetic course of reaction as that produced by unfractionated defibrinated plasma. If the above theory is correct, then both the heparin cofactor and the thrombin inactivator, as well as a trace of heparin to act as catalyst, must be present in approximately the same proportions before and after fractionation. In view of the fact that no electrophoretic component other than $\alpha$-globulin showed any antithrombin activity, both factors must belong to this plasma component. It is possible, therefore, that they possess sufficiently similar physical properties to follow one another on fractionation. Heparin may act primarily through the strong electric charge on its molecule (Jorpes, 1946), since it is known to combine with plasma proteins (Chargaff, Ziff \& Moore, 1941). It is consequently quite possible that heparin follows its cofactor on fractionation by virtue of some form of combination.

In the second place, it seems from Fig. 5 that more thrombin can be inactivated by defibrinated plasma alone, than when heparin is added to the system. The hypothesis requires the first reaction of inhibitory combination to be catalysed by heparin, and the second reaction to proceed unchanged, the 
total amount of thrombin inactivated being unchanged. To explain the discrepancy it must be pointed out that the rate of action of thrombin inactivator depends on the thrombin concentration. In the absence of heparin (Fig. 5, curve 5), the thrombin drops progressively from its initial concentration, and in the earlier stages of the reaction the rate of the decay due to the inactivator is maximal. When heparin is present in low concentration (curve 6) the thrombin concentration immediately drops to a lower level and consequently the action of the inactivator is never as rapid as in the first case, with the result that the thrombin activity remains above that for the defibrinated plasma alone after a certain period. In other words, when the two reactions are simultaneous, in the absence of added heparin, the inactivator is able to work at a higher rate than when they are consecutive.

The behaviour of the other curves in Fig. 5 can be ascribed to heparin-thrombin complex formation, if it is assumed that this complex is not susceptible to attack from the thrombin inactivator.

The hypothesis cannot, however, be taken as having been established. It is practically impossible to confirm it with the materials at present available and a more complete isolation of the two postulated substances is necessary. In the absence of such isolation the thrombin inactivator could presumably be investigated by using up all the cofactor by adding heparin, then studying the ensuing decay due to the inactivator alone; but heparin itself produces thrombin decay, at least in the preparations used here. It should similarly be possible to study the thrombin inactivator alone by removing all the heparin from the system with toluidine blue, thus rendering the cofactor inactive; but toluidine blue itself modifies the coagulant action of thrombin and produces thrombin decay. Nevertheless, it has already been mentioned that in the presence of toluidine blue the antithrombin action of defibrinated plasma is reduced, and though this observation is not capable of quantitative interpretation it is in support of the proposed theory.

The situation then is that there is no evidence directly opposed to the hypothesis, and no clear-cut evidence which can be considered to establish it; but it can certainly be used with success in interpreting the results obtained here.

The ideas put forward here are similar to those of Gerendas (1948), who considers the action of antithrombin to consist of two parts, an immediate absorption followed by a progressive inactivation, considered to be enzymic. Examination of his work, however, shows that the immediate absorption which he considers, is the non-progressive effect of strong solutions of defibrinated plasma in delaying coagulation, which persists after the defibrinated plasma has been heated to $67^{\circ}$ for $10 \mathrm{~min}$. This may well be an inhibitory absorption of thrombin, but it is reversible and has no part in the antithrombin action of defibrinated plasma in the concentrations used in the present experiments, except when specifically mentioned. It may be described as an antithrombin effect, but it is not the one with which this paper is concerned. The subsequent progressive inactivation mentioned by this author is the one that has been studied here, and shown to be complex.

It is clear that any analysis of the kinetics of the reaction between thrombin and defibrinated plasma must await separation of the two factors involved. In the present situation, where the contribution of each is not known, mathematical formulation is not feasible.

\section{SUMMARY}

1. The antithrombin action of heparin on human thrombin has been studied, with and without the addition of defibrinated plasma.

2. Heparin in concentrations above $2 \cdot 0$ units $/ \mathrm{ml}$. forms a reversible complex with thrombin. This complex has less thrombin activity than free thrombin.

3. Heparin in concentrations above $0.1 \mathrm{unit} / \mathrm{ml}$. catalyses a rapid combination between thrombin and a cofactor present in defibrinated plasma.

4. Heparin cofactor and the normal antithrombin of plasma are shown to be related but not identical, both occurring in the $\alpha$-globulin fraction.

5. A theory suggesting that normal antithrombin consists of heparin cofactor as well as another independent thrombin inactivator is proposed to account for the observed facts.

My thanks are due to Dr R. A. Kekwick for much helpful advice and encouragement; to him and Miss M. Mackay for supply of human blood products; and to Dr I. A. Galloway, Ministry of Agriculture Research Station, Pirbright, for supply of ox blood.

\section{REFERENCES}

Brinkhous, K. M., Smith, H. P., Warner, F. D. \& Seegers, W. H. (1939). Amer. J. Physiol. 125, 683.

Chargaff, E., Ziff, M. \& Moore, D. H. (1941). J. biol. Chem. $139,383$.

Gerendas, M. (1948). Hung. acta physiol. 1, 7.

Jaques, L. B., Monkhouse, F. C. \& Stewart, M. (1949). J. Physiol. 109, 41.

Jorpes, J. E. (1936). Acta med. scand. 88, 427.

Jorpes, J. E. (1946). Heparin in Thrombosis. Oxford University Press.

Lyttleton, J. W. (1954). Biochem. J. 58, 8.

MacLean, J. (1916). Amer. J. Physiol. 41, 250.

Michaelis, L. (1930). J. biol. Chem. 87, 33.

Murray, G. D. W. \& Best, C. H. (1938). J. Amer. med. Ass. $110,118$.

Quick, A. J. (1938). Amer. J. Physiol. 123, 712.

Seegers, W. H. (1942). Science, 96, 300. 